\title{
Different Polyphenolic Parenchyma Cell and Phloem Axial Resin Duct-Like Structure Formation Rates in Cupressus sempervirens Clones Infected with Seiridium cardinale
}

\author{
G. Della Rocca, ${ }^{1}$ I. Posarelli, ${ }^{2}$ F. Morandi, ${ }^{3}$ C. Tani, ${ }^{3}$ S. Barberini, ${ }^{1}$ R. Danti, ${ }^{1,}$ S. Moricca, ${ }^{2}$ and A. Papini ${ }^{3}$ \\ ${ }^{1}$ Istituto per la Protezione Sostenibile delle Piante, Consiglio Nazionale delle Ricerche, 50019 Sesto Fiorentino, Italy \\ ${ }^{2}$ Dipartimento di Scienze e Tecnologie Agrarie, Alimentari, Ambientali e Forestali, Università di Firenze, 50144 Firenze, Italy \\ ${ }^{3}$ Dipartimento di Biologia, Università di Firenze, 50121 Firenze, Italy
}

\begin{abstract}
The aim of this study was the characterization of constitutive and induced defense mechanisms in the bark tissues of Cupressus sempervirens before and after infection with the bark fungus Seiridium cardinale, which is responsible for cypress canker disease. The time-course development of polyphenolic parenchyma (PP) cells and phloem axial resin duct (PARD)-like structures in the phloem was investigated in two C. sempervirens clones, one resistant and one susceptible to the disease, through anatomical and histological observations carried out by light microscope during a 19-day trial. PP cells were constitutively more

clones as a response to infection, but in the $\mathrm{R}$ clone, they were more abundant 5 and 12 days after inoculation. After inoculation, PARDlike structures appeared in the phloem after 5 days in the $\mathrm{R}$ clone and only after 12 days in the $\mathrm{S}$ clone. Even the number of cells surrounding the PARD-like structures was higher in the R clone 5 and 12 days after inoculation compared with the $\mathrm{S}$ clone. These observations demonstrate a faster phloem response of the R clone in the early phase of the infection. This may slow down initial growth of the fungus, contributing to the resistance mechanism.
\end{abstract} abundant in the canker-resistant clone ( $\mathrm{R}$ clone) compared with the susceptible clone (S clone), whereas PARD-like structures were not present in the bark of untreated plants of both clones. PP cells increased in both
Keywords: bark canker, clone, cypress, invasive fungal pathogen, phloem, resistance, susceptibility
Trees protect themselves from pathogens through two kinds of mechanisms: structural elements acting as physical barriers and biochemical reactions that take place in the cells and tissues of the plant and produce molecules toxic to the pathogen (Agrios 2005). In the bark of conifers, this multilevel defensive system has spatial and temporal components. The spatial component is determined by the arrangement of the constitutive (preinfectional) defenses from the periderm surface to the cambial zone, whereas the temporal component consists of the continuous or temporary production of induced (postinfection) defenses in new tissues, sometimes with de novo production of new chemicals (Franceschi et al. 2005).

In Pinaceae, which represent the most studied family of conifers, bark tissues include the periderm and the secondary phloem, which provide a sophisticated defensive barrier from invading organisms, even if they contain weak points such as lenticels and parenchymal rays through which pathogens can penetrate and spread. The secondary phloem is an important site of constitutive defense mechanisms and contains sclerenchyma, calcium oxalate crystals, and phenolic compounds, although amounts vary between species (Hudgins and Franceschi 2004; Hudgins et al. 2003b). The bark of conifers is also characterized by the presence of axial parenchyma cells, known as polyphenolic parenchyma (PP) cells, which are specialized for the synthesis and accumulation of phenolic compounds (Krokene et al. 2008a). In Pinaceae, the PP cells are organized in concentric rows in the secondary phloem, separated by rows of sieve cells (Franceschi et al. 1998; Krekling et al. 2000). In non-Pinaceae, PP cells and parenchymatic rays are positioned similarly, whereas sieve cells are few, thickened, and intersected by an almost complete tangential row of sclerenchyma fibers (Hudgins et al. 2003a, 2004a).

${ }^{\dagger}$ Corresponding author: R. Danti; roberto.danti@ipsp.cnr.it

The author(s) declare no conflict of interest.

Accepted for publication 25 April 2021.

@ 2021 The American Phytopathological Society
The PP cells are involved in a series of inducible defense responses, including the activation of existing cells, the production of de novo extra PP cells, and the formation of the wound periderm. The new PP cells may be induced to develop from undifferentiated parenchyma cells (Krekling et al. 2000, 2004; Krokene et al. 2003).

Another particularly important constitutive defense in Pinaceae is resin production in preformed structures, such as radial resin ducts derived from radial parenchyma rays, axial resin ducts, resin vesicles, or resin pockets (blisters) (Hudgins et al. 2003a, 2004a). Ducts and vesicles are internally coated with plastid-enriched epithelial cells that synthesize terpenoids (major components of resin) in the extracellular lumen, where they accumulate under pressure. In cases of damage caused by mechanical injury or an invading organism, the pressurized resin is released to repel, trap, or kill (because of its toxic nature) the pathogen or insect (Celedon and Bohlmann 2019).

Like PP cells, resin ducts can also be part of the inducible defense system because the so-called traumatic resin ducts (TRDs) may be formed in the xylem of Pinaceae and axial resin ducts may be formed in the xylem and phloem of non-Pinaceae after a bark injury or pathogen/herbivore attack (Krokene et al. 2008a). In the Cupressaceae family, the phloem is characterized by a well-organized and repeated pattern in which albuminous cells interposed between tangential lines of fibers can accumulate phenols and evolve into PP cells when stimulated (Hudgins et al. 2004a; Ponchet and Andreoli 1990; Spanos et al. 1999).

Common cypress (Cupressus sempervirens L.) is a multipurpose tree with considerable economic and landscape importance that represents an important component of Mediterranean culture. Over the centuries, it has been appreciated for multiple uses in forestry and agricultural and ornamental fields (Farahmand 2020; Xenopoulos et al. 1990). Since the 1950s, this species has been decimated by the insurgence and spread of a pandemic known as cypress canker disease (CCD) caused by the invasive necrotrophic fungal pathogen Seiridium cardinale (Wagener) Sutton and Gibson, which has significantly reduced the use and cultivation of common cypress worldwide (Danti and Della Rocca 2017; Danti et al. 2013a; Graniti 1998).

For this reason, a genetic improvement program for cypress resistance to CCD was instigated in the 1970s in Italy at the Istituto per la Protezione Sostenibile delle Piante, Consiglio Nazionale delle 
Ricerche (IPSP-CNR) of Florence to counter the rapid epidemic spread of the disease, which was threatening woods, windbreaks, and ornamental plantations (Danti et al. 2011; Raddi and Panconesi 1981). Over the years, a series of canker-resistant varieties of $C$. sempervirens was selected and patented (Danti et al. 2006, 2013b; Panconesi and Raddi 1991a).

Resistance to CCD is a quantitative genetic character with polygenic control and is mainly based on the ability of plants to quickly produce a thick and continuous barrier capable of compartmentalizing the damaged and infected tissues initially through the development of a ligno-suberized boundary zone followed by a necrophylactic periderm (Danti et al. 2018; Ponchet and Andreoli 1990; Spanos et al. 1999). By restoring the continuity of the periderm, resistant trees are able to heal the lesion and recover (Panconesi and Raddi 1991b).

C. macrocarpa was found to react to infections of bark pathogens at the phloem level through two inducible defense mechanisms: the accumulation of PP cells and the production of PARD (Hudgins et al. 2004a; Krokene et al. 2008b). According to Krokene et al. (2008a), most Cupressaceae do not have preformed resin structures in either the xylem or phloem, whereas induced structures appear after a stimulus in the phloem, as also reported in C. sempervirens (Moriondo 1972; Ponchet and Andreoli 1990). A work involving C. sempevirens has demonstrated an increased production of terpenoids and qualitative changes in their composition after $S$. cardinale infection (AchoteguiCastells et al. 2015, 2016). Both mechanisms have been observed but not fully characterized from a quantitative and temporal perspective.

The aim of this work is the characterization of the constitutive and early induced defenses, at an anatomical and histological level, in the bark tissues of two cypress clones selected on the basis of resistance and susceptibility to the fungal pathogen $S$. cardinale. This study investigated the differentiation, spatial distribution, and time-course accumulation of PP cells and the genesis of PARD-like structures in the two clones inoculated with $S$. cardinale through observation using light microscopy over a period of 19 days.

\section{Materials and Methods}

Plants and fungal strains. In this study, two C. sempervirens genotypes, one resistant $(\mathrm{R})$ clone and one susceptible $(\mathrm{S})$ clone to $\mathrm{CCD}$, were considered. The two clones, which were maintained in the IPSPCNR clonal collection, were PM322, patented as being resistant to CCD with the name 'Bolgheri', and the clone PM3083, which is susceptible to the disease. Eighteen 2-year-old grafts (ramets; nine per clone) were used. The two clones were grafted in January on 1-yearold C. sempervirens seed rootstocks grown in small pots containing a mixture of peat, compost, and perlite $(3: 1: 1$, vol/vol/vol). Grafts were kept in a greenhouse until the end of spring and then transplanted into larger pots ( 4 to 5 liters) and kept for 1 year in a shade netting tunnel.

At the beginning of the experiment, plants had a mean height of $80 \pm$ $9 \mathrm{~cm}$ and a mean diameter of $1.4 \pm 0.2 \mathrm{~cm}$ at the base of the stem. The S. cardinale isolate used for the stem inoculation was the ATCC 38654 (American Type Culture Collection), a standard isolate used by the IPSP-CNR in screening trials for cypress canker resistance. This isolate was grown on petri dishes containing $2 \%$ potato dextrose agar for 14 days in the dark at $25 \pm 0.7^{\circ} \mathrm{C}$ for inoculations. One control plant (T0) for each clone was left untouched, while the other plants were stem inoculated (May 2018) following the standard procedure described in Danti et al. (2014). On each cypress plant, the inoculations were carried out where the stem was $1 \mathrm{~cm}$ in diameter and then were sampled for light microscope (LM) observations.

Sampling and preparation of samples for LM observations. Plants were sampled at four different times: shortly before inoculation (T0 = control) and 5, 12, and 19 days after inoculation (T5, T12, and T19, respectively). One 1-cm-thick stem segment per plant, including the inoculation point, was cut and mounted in resin (see below). By using a rotary microtome (Reichert-Jung), transverse sections of the stems were obtained $\sim 2 \mathrm{~mm}$ above and below the inoculation site. All sections included phloem, vascular cambium, and xylem (Fig. 1). These transverse sections were divided into four to five wedges, and the external part of each slice was used for subsequent observation under an LM.

Observations were performed under a Leitz DM-RB Fluo Light Microscope equipped with a digital camera Nikon DS-L1. The fixation procedure was similar to that reported by Dörken (2012) for Metasequoia. The transverse sections were fixed in formalin $4 \%$, acetic acid $2 \%$, and alcohol $70 \%$ for 1 week at $4^{\circ} \mathrm{C}$. The samples were washed in $70 \%$ ethanol for a few hours and dehydrated in a series of ethanol solutions of increasing purity ( 80 and $95 \%$, absolute alcohol 1 and absolute alcohol 2, respectively; $1 \mathrm{~h}$ for each step). Two preinclusions then were made in absolute alcohol and Tecnovit 7100 resin (Kulzer) $1: 1$ and in $1: 2$ ratios for $2 \mathrm{~h}$ each at room temperature. Finally, the samples were transferred to pure resin overnight. The day after, samples were placed inside sealed polypropylene capsules and mounted in pure resin and hardener/catalyst (15:1 ratio) at room temperature. Slides of the resin included samples cut with a Heidelberg rotary microtome (Reichert-Jung). The sections, which were $\sim 4 \mu \mathrm{m}$ thick, were stained with toluidine blue $(0.5 \%$ toluidine with addition of $0.1 \%$ sodium, $\mathrm{pH} 11$ ) for observation using the LM. Toluidine blue is a metachromatic dye that gives a color ranging from purple red (which stains the cellulose structures) to blue (which stains the lignified structures) (Trump et al. 1961). This dye also can be used for identifying phenols and lipids in a comparable way with respect to more specific staining, such as potassium dichromate and SUDAN Black B, respectively (Ribeiro and Leitão 2020).

Defense-related features observed with LM. For each cypress clone and each sampling date, five to eight sections were observed at a magnification of $\times 200$. For each section, three to five pictures were taken by placing the cambium on the ordinate axis and moving from left to right to cover the entire width of the section without overlapping. For each picture taken on the transverse section of cypress bark, a series of anatomical elements related to plant defense were observed and evaluated. Among the constitutive defense elements (a), we investigated (a1) the number of fiber lines per millimeter of phloem thickness and (a2) the number of parenchyma rays observed per millimeter of phloem width. Among the inducible defenses (b), we considered (b1) the total number of PP cells per $0.1 \mathrm{~mm}^{2}$ and (b2) the percentage of single and aggregated (coupled, in triplet or in blocks of $>3$ units) PP cells. We evaluated (b3) the number of PARD-like structures per millimeter of phloem width (regardless of their maturity), (b4) a development index (DI) of PARD-like structures (see below), and (b5) the number of internal cells coating every single PARD-like structure.

To evaluate the state of maturation of the inducible PARD-like structure, their development was divided into three arbitrary phases based on our observations: an initial phase (the PARD-like structure started to form from an initial elongation in the radial sense of the phloem parenchyma cells and by the progressive reduction in volume

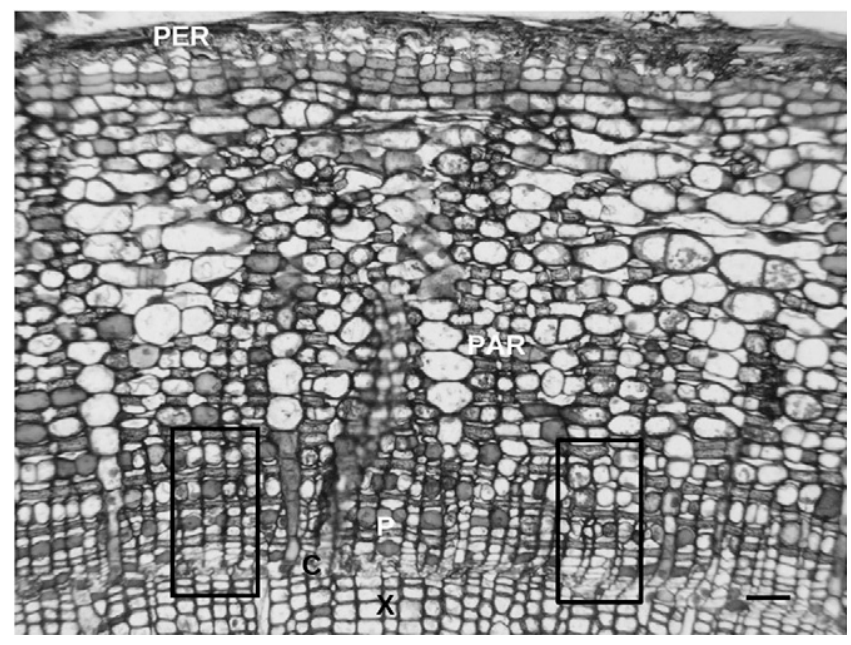

Fig. 1. Image of cypress stem cross-sections observed with light microscope (original magnification $\times 100$ ). Squares in black lines represent the sampling area, including secondary xylem, cambium, and secondary phloem. C, cambium; $P$, secondary phloem; PAR, parenchyma; PER, periderm; X, xylem. Bar $=50 \mu \mathrm{m}$. 
and disappearance of the phloem cells); an intermediate phase (degradation of the phloem cells and detachment of the middle lamella with formation of the resin duct); and an advanced phase (with the formation of a single large resin cavity) (see Fig. 6). The three phases were scored as 1,2 , and 3 , respectively. The DI was, therefore, calculated as follows:

$$
\begin{aligned}
\text { DI }(\text { PARD })= & (\mathrm{n} . \text { PARD initial phase } \times 1) \\
& +(\mathrm{n} . \text { PARD intermediate phase } \times 2) \\
& +(\mathrm{n} . \text { PARD advanced phase } \times 3) .
\end{aligned}
$$

Statistical analysis. The data obtained through LM observations were analyzed by one-way ANOVA to test separately how the time (four levels: T0, T5, T12, T19) and the clone (two levels: resistant or susceptible) factors affected the defense response induced in cypress. Means were compared using the honestly significant difference post hoc test for unequal $N$ or Tukey test for $P<0.05$ to highlight which combinations of means were significantly different from the others. The condition of homogeneity of variance was previously verified with Levene's test. For the statistical analysis, the percentages were transformed according to the Bliss formula (arcos $\times$ square root of percentages). All statistical analyses were performed with STATISTICA 10.0 software.

\section{Results}

Defense-related features/parameters observed with LM. Before inoculation (T0), the transverse sections of the cypress stem of both clones showed a structure typical of the Cupressaceae. Of particular relevance was the structure of the secondary phloem, which was composed of radial columns of cells formed by a repeated pattern of sclerenchyma fiber > cell 1 (putative phloem element) > cell 2 (putative albuminous cell) $>$ cell 1 (phloem element) $>$ sclerenchyma fiber again, whereas other radial columns of cells were comprised of parenchymatic cells (Fig. 2). Regardless of the genotype, a relatively small number of PP cells were present in the bark tissues although PARD-like structures were not visible.

Constitutive defense systems. In the $\mathrm{R}$ clone, the number of fiber layers in the phloem $(\mathrm{R}=\mathrm{PM} 322)$ was significantly higher than in the $\mathrm{S}$ clone $(\mathrm{S}=\mathrm{PM} 3083 ; 28.0$ versus 22.9 per $\mathrm{mm}$, respectively; $P<0.01$ ). In contrast, the number of radial parenchyma rays found in the phloem tissue was not significantly different between the clones (12.9 versus 13.8 per $\mathrm{mm}$ in $\mathrm{R}$ and $\mathrm{S}$ clones, respectively). The number of PP cells

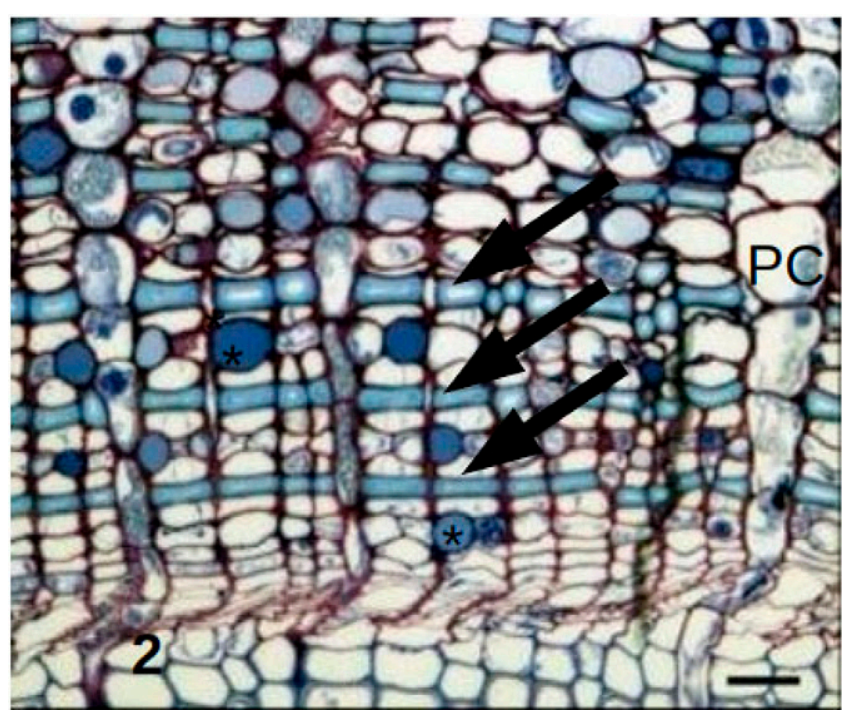

Fig. 2. The typical structure of secondary phloem in Cupressus sempervirens in a transverse section of intact stem is composed by radial columns of cells formed by a repeated pattern: sclerenchymatic fiber (arrows) $>$ cell $1>$ cell $2>$ cell $1>$ sclerenchymatic fiber again. Other radial columns of cells contain parenchymatic cells. Some polyphenolic parenchyma cells (asterisks) are visible between the sclerenchymatic rows. PC, parenchyma cells. Bar $=25 \mu \mathrm{m}$. per surface unit $\left(0.1 \mathrm{~mm}^{-2}\right)$ was significantly higher in the $\mathrm{R}$ clone compared with the $\mathrm{S}$ clone (40.7 and 33.0, respectively; $P<0.05$ ) (Fig. 2).

Inducible defense systems. $P P$ cells. After inoculation with the fungal pathogen $S$. cardinale, some phloem parenchyma cells (possibly albuminous cells) progressively evolved into PP cells, filling their vacuoles with polyphenols. The differentiation of these cells into PP cells occurred quickly (5 days from infection) and progressively increased over time (Fig. 3). PP cells derived from a cell in the position normally occupied by albuminous cell (Fig. 3i) started to accumulate polyphenols (Fig. 3ii) and eventually crushed the phloem elements (Fig. 3iii). The newly developed PP cells appeared to be arranged in layers within the phloem tissues, regardless of the distance from the cambium. The number of PP cells in the secondary phloem increased over time as single cells or in groups of two, three, or more contiguous cells along a same row (Fig. 4).

In both cypress genotypes, the total number of PP cells (per 0.1 $\mathrm{mm}^{2}$ ) increased in response to infection from 33.03 (T0) to 53.08 (T19) and from 40.7 (T0) to 54.2 (T19), respectively, in clones S and R. However, within both clones a significant difference $(P<$ 0.01) was only observed between T0 and T19 (Fig. 5). Regarding the comparison between genotypes, the number of PP cells was always higher in the $\mathrm{R}$ clone compared with the $\mathrm{S}$ clone (T0, $P=0.026$; T5, $P<0.01$; T12, $P<0.01$, respectively), except at T19 (Fig. 5).

The percentage of aggregated PP cells progressively increased in both clones in response to infection, ranging from $28.4 \%$ (T0) to $41 \%$ (T19) in the S clone $(P<0.01)$ and from $21.5 \%$ (T0) to $34 \%$ (T19) in the R clone $(P<0.01)$. At T5 and T19, the $\mathrm{S}$ clone showed a higher percentage of aggregated PP cells than the R clone (38 versus $27 \%$ at $\mathrm{T} 5$ and 34 versus $41 \%$ at T19; $P<0.01$ and $P=0.015$, respectively).
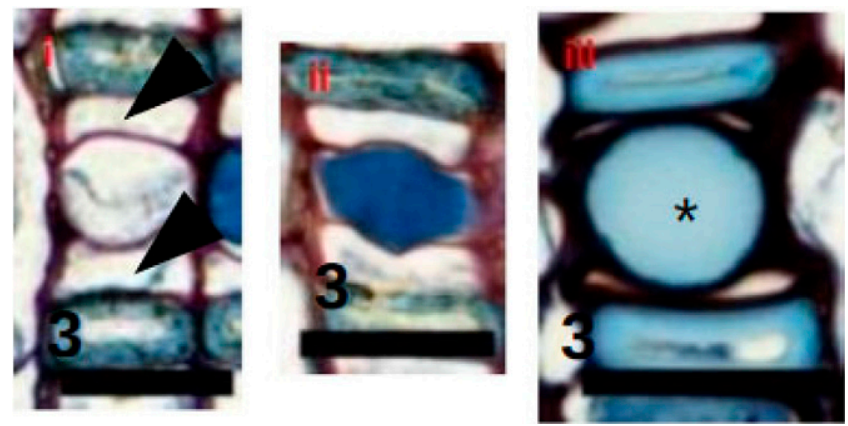

Fig. 3. Progressive evolution of a phloem parenchyma cell until it is filled with polyphenols, stained with toluidine blue. $\mathbf{i}$, The phloem parenchyma cell is between two functional phloem elements (arrowheads). ii, This cell begins to accumulate polyphenols while the adjacent cells appear unaffected, iii, This cell (asterisk) is filled with polyphenols while the adjacent elements appear to be crushed and no longer functional. $B a r=25 \mu \mathrm{m}$.

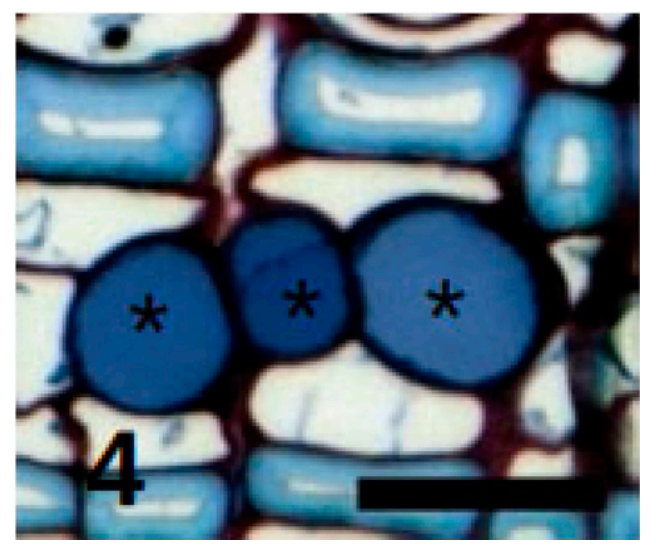

Fig. 4. Polyphenolic parenchyma cells (asterisks) in the secondary phloem can be contiguous along a same row. Bar $=25 \mu \mathrm{m}$. 
PARD-like structures. PARD structures were absent in the phloem of both cypress clones before infection with $S$. cardinale (T0). PARDlike structures developed between 5 and 12 days after inoculation between the second and third line of fibers from the cambium. PARD-like structures formed less frequently between the first and the second line of sclerenchymatic fiber starting from the cambium because of the detachment of fibers from the adjacent cells that apparently degenerated by crushing or reducing in volume (Fig. 6A and B). Thus, an intercellular space formed, surrounded by phloem parenchyma cells (Fig. 6C and D). PARD-like structures appeared between two parenchyma rays, generating from an initial elongation of the parenchyma cells in a radial sense (Fig. 6A). The division of these cells occurred even if they accumulated polyphenols, the latter apparently decreasing during the process. After mitosis of the phloem parenchyma cells, their middle lamella detached, generating a wide intercellular space (Fig. 6B). In a more advanced phase (on average between 12 and 19 days after infection), the parenchyma ray cells on the sides of the forming PARD divided periclinally; in the final phase, the line of sclerenchyma cells also broke, leading to the formation of a single large resin cavity (Fig. 6D). The cells surrounding the duct split, and those toward the duct stained bright with toluidine blue. Organic material (putative resin) was visible in the PARD-like structures (Fig. 6D).

In response to infection in both genotypes, the number of PARDlike structures per linear millimeter of bark tissues parallel to cambium increased from 0 to 4.3 at T19 in clone $\mathrm{S}$ and to 3.8 at T19 in clone R $(P<0.01)$ (Fig. 7). At T5 we observed a greater number of PARD-like structures in clone $\mathrm{R}\left(0.6 \mathrm{~mm}^{-1}\right)$ compared with clone $\mathrm{S}$, which still did not show any (Fig. 7), although no other differences between clones were observed over time. The DI of PARD-like structures increased in response to infection in both clones, with values starting from 0 and reaching 3.9 at T19 in clone $\mathrm{S}$ and 4.4 in clone R (T19) (Fig. 8). DI increased slowly from T5 to T19 in clone S, whereas in clone R it increased more rapidly from $\mathrm{T} 0$ and reached its maximum at $\mathrm{T} 12$ $(P<0.01)$ (Fig. 8). In both genotypes at T5 and T12, the DI was higher in the $\mathrm{R}$ clone compared with the $\mathrm{S}$ clone (at $\mathrm{T} 5, \mathrm{~S}$ clone did not show any PARD-like structure yet): 0.3 versus 0 at T5 $(P<0.01)$ and 3.9 versus 2.7 at T12 ( $P=0.015)$, respectively (Fig. 8$)$. Finally, the total number of cells coating the PARD-like structures per linear millimeter of bark tissue parallel to the cambium increased in both clones after infection (from 0 at T0 up to 104.8 at T19 in clone S; from 0 at T0 up to
110.5 at T19 in R) (Fig. 9). In clone R, the increase was gradual and the maximum value was reached at T12 $(P<0.01)$, whereas in clone $\mathrm{S}$, which did not have PARD-like structures at T5, the maximum number of coating cells was detected at T19 $(P<0.01)$. Comparing clones, we observed that only at T5 and T12 were the number of coating cells significantly higher in clone $\mathrm{R}$ than in clone $\mathrm{S}(P<0.01)$ (Fig. 9).

\section{Discussion}

In this work, we observed at anatomical level the time-course genesis of the PARD-like structures and PP cells in the bark tissues of canker-resistant and -susceptible $C$. sempervirens clones infected

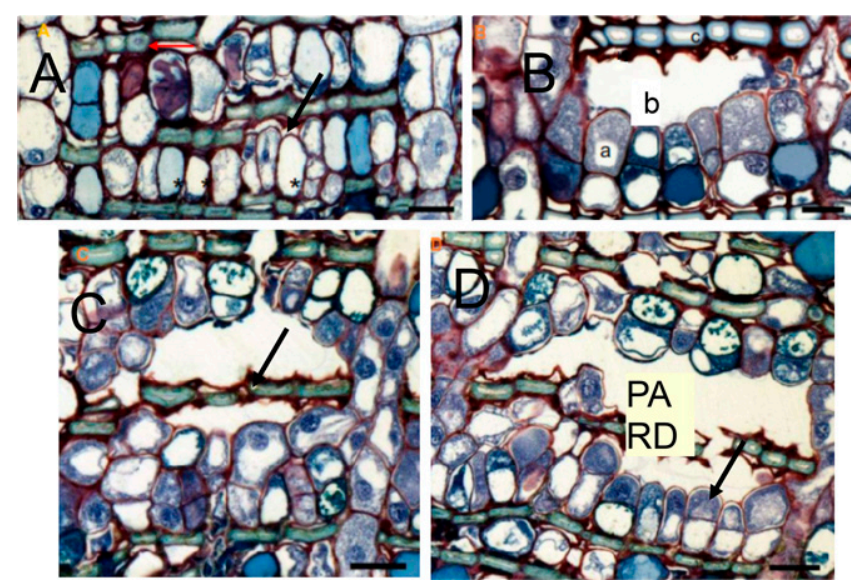

Fig. 6. A, Initial, B and C, intermediate, and D, final stage of development of an inducible phloem axial resin duct (PARD)-like structure in Cupressus sempervirens bark tissues. A, Beginning of degeneration of the phloem cells (black arrow) close to the sclerenchyma cells (red arrow). The phloem parenchyma cells (asterisks) are beginning to modify their cytoplasm content. B, a, The phloem parenchyma cells are changing their color and becoming more toluidine blue positive, while $\mathbf{B}, \mathbf{b}$, the space formed by the degeneration of the phloem elements expands. B, c, The sclerenchyma elements maintain their position. C, The PARD-like structure is formed on both sides of the sclerenchymatic fibers (arrow) row. D, A row of phloem parenchyma cells (arrow) surrounding the resin duct (PARD) has changed, and cytoplasm is completely stained with toluidine blue. Bar $=25 \mu \mathrm{m}$.

\section{N. PP cells / $0.1 \mathrm{~mm} 2$}

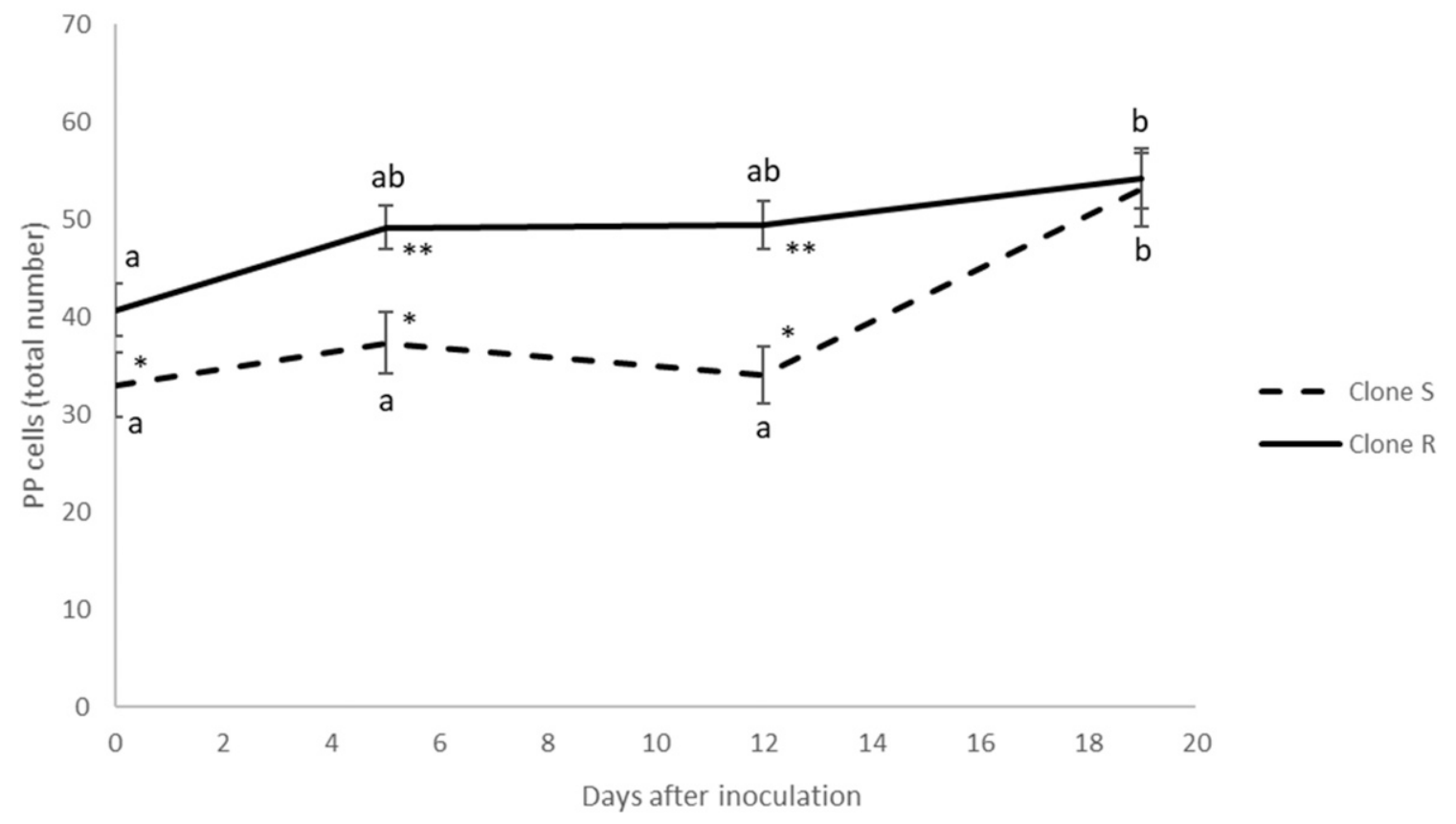

Fig. 5. The number of polyphenolic parenchyma cells detected in $0.1 \mathrm{~mm}^{2}$ of cross-section of secondary phloem in susceptible and resistant cypress clones at time 0 (preinfection) and 5,12 , and 19 days after artificial inoculation with the fungal pathogen Seiridium cardinale. Different letters indicate significant differences among sampling times within the same clone. Asterisks indicate significant differences between clones at the same sampling time. Bars represent the standard error. 
with $S$. cardinale. Our observations evidenced that the phloem of the $C$. sempervirens canker-resistant clone is characterized by a higher number of constitutive PP cells and by a faster formation of both new PP cells and PARD-like structures after $S$. cardinale infection, compared with the susceptible clone.

In conifers, including Cupressaceae, the synthesis of phenolic compounds and the formation of PP cells are important components of phloem defense (Krokene et al. 2008a). The development and structural characterization of PP cells, as well as the timing of this process, have not been well studied in many species, including $C$. sempervirens. In our study, scattered PP cells were constitutively observed in both cypress clones, but their frequency was significantly higher in the $\mathrm{R}$ clone at T0. In 2-year-old stems of both clones, we observed multiple rings of PP cells (at least five to six were still clearly visible), which excluded an annual production of PP cells limited to a single ring, similarly to observations in Taxodium distichum that also belongs

\section{Number of PARD-like structures / mm}

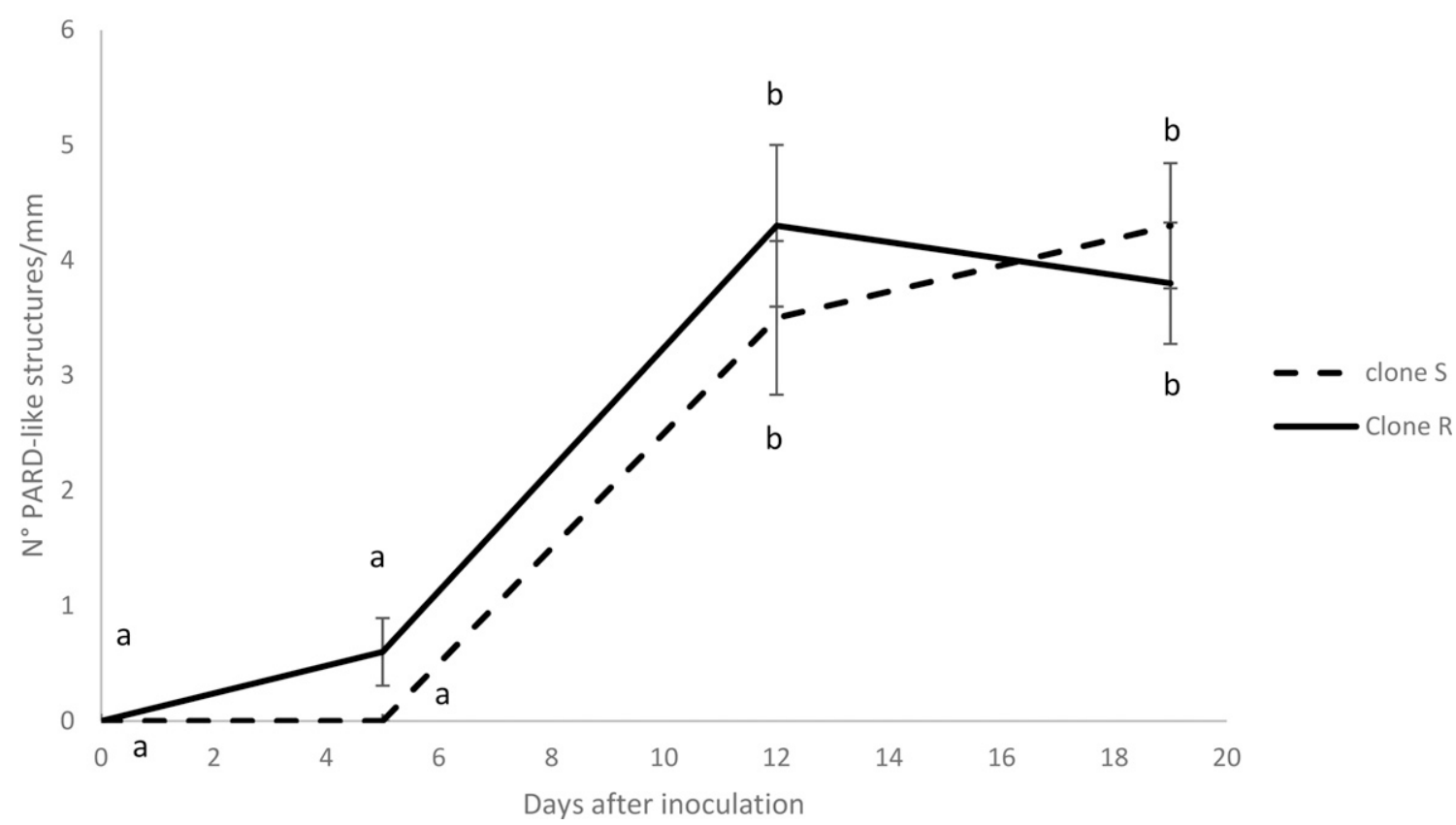

Fig. 7. Number of phloem axial resin duct (PARD)-like structures detected on linear millimeters of bark tissue (parallel to cambium) in susceptible (S) and resistant (R) cypress clones at time 0 (preinfection) and 5,12, and 19 days after artificial infection with Seiridium cardinale. Different letters indicate significant differences between the sampling times within the same clone. Bars represent the standard error.

\section{DI of PARDs-like structures}

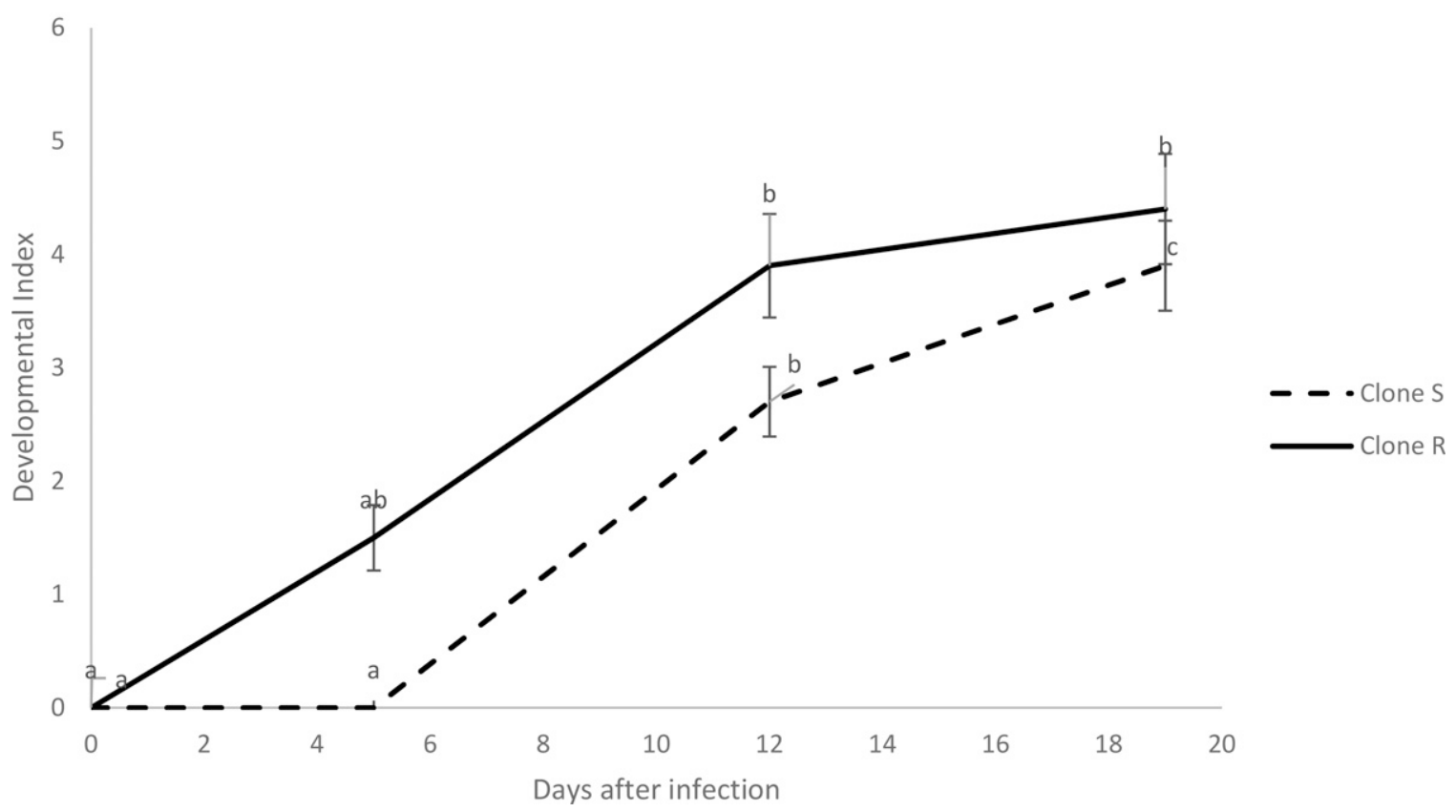

Fig. 8. Development index (DI) of phloem axial resin duct (PARD)-like structures in susceptible (S) and resistant (R) cypress clones at time 0 (preinfection) and 5, 12, and 19 days from artificial infection with Seiridium cardinale (see Materials and Methods for explanation). Different letters indicate significant differences between the sampling times within the same clone. Asterisks indicate significant differences between clones at the same sampling time. Bars represent the standard error. 
to the Cupressaceae family (Krokene et al. 2008a). In contrast, in Pinaceae, PP cells are commonly arranged in concentric rows within each annual tangential ring of secondary phloem growth and are separated by nine to 12 rows of sieve cells (Krekling et al. 2000, 2004; Krokene et al. 2003, 2008a).

In this study, the PP cell response of the R clone was observed 5 days after infection and the increase in PP cells was generally gradual during the experiment. In contrast, the $\mathrm{S}$ clone showed a delayed postinfection increase in PP cells. Production of new PP cells in response to various stimuli (e.g., wounds, attacks of xylophagous beetles, fungal infection) was observed in the secondary phloem of many conifers (Hudgins et al. 2003a, 2004; Krekling et al. 2004). In C. macrocarpa, an increase of approximately fivefold was observed 7 weeks from exogenous treatment with methyl jasmonate, an elicitor hormone that mimics a fungal infection (Hudgins and Franceschi 2004; Hudgins et al. 2004). The same authors showed a $40 \%$ increase in the average size of PP cells in Monterey cypress. Krokene et al. (2003) also observed an increase in PP cells in Picea abies, covering up to $50 \%$ of the phloem section 15 days after a massive bark inoculation with the fungus Ceratocystis polonica. In other Cupressaceae, such as Chamaecyparis obtusa, 2 weeks after a wound stimulus, both an increase in volume of the preexisting PP cells by hypertrophy and an increase in the number of PP cells were observed in the secondary phloem (Kusumoto and Suzuki 2003), Similar to our results, a greater increase in PP cells in the secondary phloem of resistant $(>40 \%)$ compared with susceptible clones was observed in $P$. abies after infection with the pathogenic fungus $C$. polonica (Franceschi et al. 1998), confirming that induced PP cells are involved in the defense of the phloem from invading organisms (Hudgins et al. 2004).

Our LM observations demonstrated that in C. sempervirens, new PP cells originated from phloem parenchyma cells through accumulation of phenolic substances in the vacuole. These new PP cells developed in the phloem 5 days after artificial inoculation with $S$. cardinale without a preferential zone of accumulation. The same origin has been described by Fahn (1990), Krekling et al. (2000), and Krokene et al. (2008b) in P. abies. As a consequence of the increase in volume and number of PP cells, the adjacent sieve cells were progressively crushed and became nonfunctional, as also reported by Franceschi et al. (2005) and Krokene et al. (2008a) in the phloem of 3- to 4-year-old spruce. In this study, we observed that the sieve cells started to be crushed beyond the fourth line of fibers from the cambium outward after PP cell enlargement.

A clear timing difference was observed between clones $\mathrm{S}$ and $\mathrm{R}$ in the beginning of PARD-like structure formation after infection with $S$. cardinale. In the R clone, PARD-like structure formation began 5 days after inoculation, whereas in the $\mathrm{S}$ clone, PARD-like structures developed only after 12 days. Other authors have also highlighted that number and speed of PARD generation is related to pathogen or pest resistance. Indeed, Krokene et al. (2008b), Nagy et al. (2000), and Tomlin et al. (1998) reported that $P$. abies clones resistant to $C$. polonica and P. glauca clones resistant to the beetle Pissodes strobi showed a faster development of higher numbers of TRDs compared with susceptible clones. Another study showing the significant relationship between clone resistance and number of TRDs produced after infection was published by Ferrenberg et al. (2014) on Pinus contorta and Pinus flexilis, although those cases referred to Pinaceae and therefore, to xylem TRDs.

The second important factor involved in conifer pathogen defense is based on terpenoids (Celedon and Bohlmann 2019, Krokene et al. 2008a). Many conifers show preformed resin-producing structures in the secondary phloem or in the secondary xylem as constitutive defenses (Hudgins and Franceschi 2004).

Cupressaceae do not have preformed resin structures either in the xylem or phloem, although induced structures appear after a stimulus in the xylem (Sequoia sp., Sequoiadendron sp., Metasequoia sp.) or in the phloem (Cupressus, Chamaecyparis, Cryptomeria), depending on the genus (Krokene et al. 2008a). According to our observations, C. sempervirens did not present any resiniferous duct before infection. PARDs are part of the complex, rapid, coordinated defense response in conifers. To the best of our knowledge, induction and development of PARDs as well as their timing and spatial distribution have never previously been studied in common cypress. In C. sempervirens, production of PARD-like structures was observed exclusively in the secondary phloem 5 to 12 days after infection with $S$. cardinale. The same process was also observed in C. macrocarpa (28 days after inoculation) and in other Cupressaceae such as Cryptomeria japonica

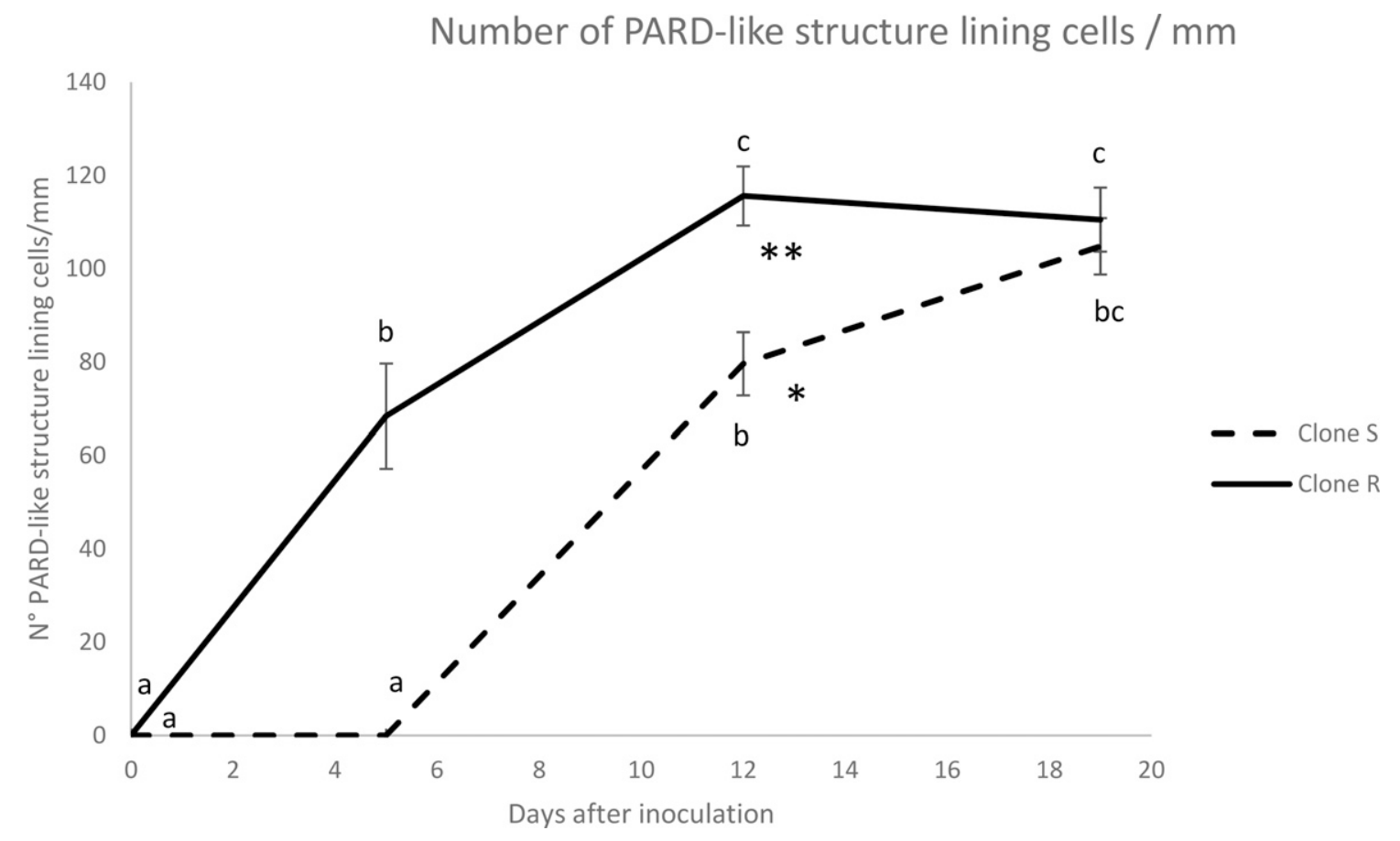

Fig. 9. The total number of lining cells internally lining the phloem axial resin duct (PARD)-like structures included in one linear millimeter of bark tissue (parallel to cambium) of susceptible (S) and resistant (R) clones at time 0 (preinfection) and 5,12, and 19 days from artificial infection with Seiridium cardinale. Different letters indicate statistically significant differences between the various times in a same clone. Asterisks indicate statistically significant differences between the two clones at the same time. Bars represent the standard error. 
(after 7 weeks; Hudgins et al. 2004), C. obtusa (5 days after fungal inoculation; Fujii et al. 2018; Kusumoto and Suzuki 2003; Suto 1998; Yamanaka 1984), and Sequoiadendron giganteum (after 28 days; Hudgins and Franceschi 2004).

In our 19-day experiment, PARD-like structures developed synchronously inside each clone, being generated almost simultaneously and arranged in lines around the third line of fibers (rarely forming in the second from the cambium). PARD-like structure formation involved complex changes in cell division activity and differentiation of different cells. The formation of PARDs in the xylem of conifers is well documented (Krekling et al. 2004; Nagy et al. 2000). In contrast, there are few reports about PARD genesis in secondary phloem of conifers and, based on our current knowledge, no studies have ever been conducted in $C$. sempervirens so far. The presence of PARD-like structures in association with fungal infection was observed in various works (Achotegui-Castells et al. 2015, 2016; Danti et al. 2018; Madar et al. 1995; Moriondo 1972; Ponchet and Andreoli 1990; Spanos et al. 1999). In fact, the exudation of resin from cankers is well known and is considered a key symptom for the identification of $S$. cardinale infection.

Extending the field to other Cupressaceae, Yamanaka (1989) reported that in C. obtusa the development of PARDs in the secondary phloem did not occur in a single line over a line of fibers but rather simultaneously in a double layer at both sides of the second line of fibers from the cambium, with the result that 21 days after the stimulus, two adjacent layers of PARDs were detectable (Yamanaka 1989). From our observations, it seemed that in common cypress the mechanism was partly similar but with substantial differences as the PARDlike structures formed over a line of fibers that in 3 weeks was lysed to form a single lumen.

Moreover, in our study, a higher number of cells lining the lumen of the PARD-like structures was observed in the R clone after 5 and 12 days from infection, compared with the $\mathrm{S}$ clone. In contrast, Krekling et al. (2004) observed that a greater number of TRDs was associated with susceptibility, hypothesizing that it could be owing to the extensive growth of the pathogen in the tissues, which would cause a greater stimulus. Kuroda (1998) noted that in C. obtusa it took at least 2 weeks to observe the full development of TRDs and resin precursor in the coating cells. In our study, PARD-like structures showed a similar timing of development, although resin precursors were not investigated.

In the area of the initial PARD-like structures formation (between the first and third lines of fibers), we observed a contextual decrease of PP cells. It is possible that during the formation of the PARD-like structures, the phloem parenchyma cells began to differentiate, while some PP cells lost their vacuolar polyphenol content. A similar phenomenon had been observed by Nagy et al. (2000) in P. abies after 36 days from wounding.

The well-defined structure pattern, based on repeated layers, observed in C. sempervirens secondary phloem in this study is typical of the Cupressaceae and has been already observed by Ponchet and Andreoli (1990) in the same species, as well as in C. macrocarpa (Hudgins et al. 2004a), C. obtusa (Suto 1998), T. disticum (Krokene et al. 2008a) and S. giganteum (Hudgins and Franceschi 2004; Hudgins et al. 2004a).

The present work highlighted a preinfection difference among the two $C$. sempervirens clones in terms of a greater number of fiber layers observed in the secondary phloem of the R clone compared with the $\mathrm{S}$ clone. This finding confirmed that sclerenchyma tissue, consisting of quadrangular closely grouped cells arranged in lines (fibers) with a well-thickened and lignified cell wall, constitutes a structural element of mechanical defense (Franceschi et al. 2005) that may vary between genotypes.

This study represents, to the best of our knowledge, the first work that provides qualitative and quantitative information on the timing of development and distribution of PP cells and PARD-like structures in the phloem tissues of $C$. sempervirens infected with the bark pathogen $S$. cardinale.

The metrics taken showed significant differences between the $\mathrm{R}$ and $\mathrm{S}$ clone, indicating that both the PP cells and the PARD-like structures are involved in the postinfection host response. Constitutive differences emerged between the two genotypes: the lignified fiber lines and the preinfection PP cells were more abundant in the $\mathrm{R}$ clone than in the $\mathrm{S}$ clone, although no PARD-like structures were visible in the control plants of both genotypes before inoculation. The postinfection defense response of the $\mathrm{R}$ clone was observed 5 days after the infection and was faster compared with the $\mathrm{S}$ clone. The increase in PP cells, both as a total number and as a percentage of aggregated ones, showed a progressive positive trend in the $\mathrm{R}$ clone. In contrast, the $\mathrm{S}$ clone showed a less marked and often delayed postinfection increase in PP cells. Nineteen days after infection, differences between the two clones substantially disappeared. Also, PARD-like structure formation in the phloem appeared more rapid in the $\mathrm{R}$ clone, being observed 5 days after infection whereas in the $\mathrm{S}$ clone, PARD-like structures were observed only 12 days after infection. Considering the results, the outcome of our study suggests that the substantial differences between the $\mathrm{R}$ clone and $\mathrm{S}$ clone are related to the speed of response to infection.

Both the PP cells and the PARD-like structures generated from phloem parenchyma cells. The genesis of PARD-like structures in the phloem of $C$. sempervirens was described here for the first time. The PARD-like structures appeared simultaneously over the third row of sclerenchyma fibers by schizogenesis and fragmentation of some cells by perforation of the dividing walls. This process was similar to that described in C. obtusa but with a difference never highlighted before relating to the positioning of PARD-like structures with respect to the fibers.

It was also confirmed that species of the genus Cupressus, like the other non-Pinaceae, are characterized by constitutive defenses consisting of PP cells and lignified fiber lines, which may vary among genotypes. The results of this study represent an advancement in knowledge of the potential mechanisms underlying the resistance of $C$. sempervirens to $S$. cardinale and could be helpful in the early selection of resistant cypress genotypes. However, further studies on an extended number of canker-resistant cypress genotypes are needed to fully associate the histological responses found in this study to resistance and susceptibility. Such studies should also be continued for a longer time to more adequately assess the response to early infection and its evolution.

\section{Literature Cited}

Achotegui-Castells, A., Danti, R., Llusià, J., Della Rocca, G., Barberini, S., and Peñuelas, J. 2015. Strong induction of minor terpenes in Italian Cypress, Cupressus sempervirens, in response to infection by the fungus Seiridium cardinale. J. Chem. Ecol. 41:224-243.

Achotegui-Castells, A., Della Rocca, G., Llusià, J., Danti, R., Barberini, S., Bouneb, M., Simoni, S., Michelozzi, M., and Peñuelas, J. 2016. Terpene arms race in the Seiridium cardinale-Cupressus sempervirens pathosystem. Sci. Rep. 6:18954.

Agrios, G. N. 2005. Plant Pathology, Vol. 922. Elsevier Academic Press, San Diego, CA.

Celedon, J. M., and Bohlmann, J. 2019. Oleoresin defenses in conifers: chemical diversity, terpene synthases, limitations of oleoresin defense under climate change. New Phytol. 224:1444-1463.

Danti, R., Barberini, S., Pecchioli, A., Di Lonardo, V., and Della Rocca, G. 2014. The epidemic spread of Seiridium cardinale on Leyland cypress severely limits its use in the Mediterranean. Plant Dis. 98:1081-1087.

Danti, R., and Della Rocca, G. 2017. Epidemiological history of cypress canker disease in source and invasion sites. Forests 8:121.

Danti, R., Della Rocca, G., Di Lonardo, V., Pecchioli, A., and Raddi, P. 2011. Genetic improvement program of cypress: results and outlook. Pages 88-96 in: Status of the Experimental Network of Mediterranean Forest Genetic Resources. C. Besacier, F. Ducci, M. Malagnoux, and O. Souvannavong, eds. CRA SEL, Arezzo and FAO, Rome, Italy.

Danti, R., Della Rocca, G., and Panconesi, A. 2013a. Cypress canker. Pages 359375 in: Infectious Forest Disease. G. Nicolotti and P. Gonthier, eds. CABI Press, Oxfordshire, England.

Danti, R., Di Lonardo, V., Pecchioli, A., and Della Rocca, G. 2013b. 'Le Crete 1'and 'Le Crete 2': two newly patented Seiridium cardinale canker-resistant cultivars of Cupressus sempervirens. For. Path. 43:204-210.

Danti, R., Raddi, P., Panconesi, A., Di Lonardo, V., and Della Rocca, G. 2006. "Italico" and "Mediterraneo": two Seiridium cardinale canker resistant cypress cultivars of Cupressus sempervirens. Hort. Science 41:1357-1359.

Danti, R., Rotordam, M. G., Emiliani, G., Giovannelli, A., Papini, A., Tani, C., Barberini, S., and Della Rocca, G. 2018. Different clonal responses to cypress canker disease based on transcription of suberin-related genes and bark carbohydrates' content. Trees (Berl.) 32:1707-1722. 
Dörken, V. M. 2012. Proliferating seed cones in Metasequoia glyptostroboides $\mathrm{Hu} \&$ Cheng (Cupressaceae s.l., Coniferales) elucidate the evolution of seed cones and ovules in Cupressaceae s.l. Feddes Repert. 122:409-420.

Fahn, A. 1990. Plant Anatomy. Pergamon Press, Oxford, United Kingdom.

Farahmand, H. 2020. The genus Cupressus L. Mythology to biotechnology with emphasis on Mediterranean cypress (Cupressus sempervirens L.). Hortic. Rev. (Am. Soc. Hortic. Sci.) 47:213-287.

Ferrenberg, S., Kane, J. M., and Mitton, J. B. 2014. Resin duct characteristics associated with tree resistance to bark beetles across lodgepole and limber pines. Oecologia 174:1283-1292.

Franceschi, V. R., Krekling, T., Berryman, A. A., and Christiansen, E. 1998. Specialized phloem parenchyma cells in Norway spruce (Pinaceae) bark are an important site of defense reactions. Am. J. Bot. 85:601-615.

Franceschi, V. R., Krokene, P., Christiansen, E., and Krekling, T. 2005. Anatomical and chemical defenses of conifer bark against bark beetles and other pests. New Phytol. 167:353-376.

Fujii, T., Osumi, K., and Kubono, T. 2018. Resin canals in "hiwada," bark of hinoki (Chamaecyparis obtusa) as roofing material. Bull. For. For. Prod. Res. Inst. 17:305-316

Graniti, A. 1998. Cypress canker: a pandemic in progress. Annu. Rev. Phytopathol. 36:91-114.

Hudgins, J. W., Christiansen, E., and Franceschi, V. R. 2003a. Methyl jasmonate induces changes mimicking anatomical defenses in diverse members of the Pinaceae. Tree Physiol. 23:361-371.

Hudgins, J. W., Christiansen, E., and Franceschi, V. R. 2004. Induction of anatomically based defense responses in stems of diverse conifers by methyl jasmonate: a phylogenetic perspective. Tree Physiol. 24:251-264.

Hudgins, J. W., and Franceschi, V. R. 2004. Methyl jasmonate-induced ethylene production is responsible for conifer phloem defense responses and reprogramming of stem cambial zone for traumatic resin duct formation. Plant Physiol. 135:2134-2149.

Hudgins, J. W., Krekling, T., and Franceschi, V. R. 2003b. Distribution of calcium oxalate crystals in the conifers: a constitutive defense mechanism? New Phytol. 159:677-690.

Krekling, T., Franceschi, V. R., Berryman, A. A., and Christiansen, E. 2000. The structure and development of polyphenolic parenchyma cells in Norway spruce (Picea abies) bark. Flora 195:354-369.

Krekling, T., Franceschi, V. R., Krokene, P., and Solheim, H. 2004. Differential anatomical response of Norway spruce stem tissues to sterile and fungus infected inoculations. Trees (Berl.) 18:1-9.

Krokene, P., Nagy, N. E., and Krekling, T. 2008a. Traumatic resin ducts and polyphenolic parenchyma cells in conifers. Pages 147-169 in: Induced Plant Resistance to Herbivory. A. Schaller, ed. Springer, Dordrecht, The Netherlands.

Krokene, P., Nagy, N. E., and Solheim, H. 2008b. Methyl jasmonate and oxalic acid treatment of Norway spruce: anatomically based defense responses and increased resistance against fungal infection. Tree Physiol. 28:29-35.

Krokene, P., Solheim, H., Krekling, T., and Christiansen, E. 2003. Inducible anatomical defense responses in Norway spruce stems and their possible role in induced resistance. Tree Physiol. 23:191-197.
Kuroda, K. 1998. Seasonal variation in traumatic resin canal formation in Chamaecyparis obtusa phloem. IAWA J. 19:181-189.

Kusumoto, D., and Suzuki, K. 2003. Spatial distribution and time-course of polyphenol accumulation as a defense response induced by wounding in the phloem of Chamaecyparis obtusa. New Phytol. 159:167-173.

Madar, Z., Gottlieb, H. E., Cojocaru, M., Riov, J., Solel, Z., and Sztejnberg, A 1995. Antifungal terpenoids produced by cypress after infection by Diplodia pinea f. sp. cupressi. Phytochem. 38:351-354.

Moriondo, F. 1972. Il cancro del cipresso da Coryneum cardinale Wag. I Contributo: la progressione del processo infettivo nei tessuti caulinari. Ann. Accad. Ital. Sci. For. 21:399-426.

Nagy, N. E., Franceschi, V. R., Solheim, H., Krekling, T., and Christiansen, E. 2000. Wound-induced traumatic resin duct development in stems of Norway spruce (Pinaceae): anatomy and cytochemical traits. Am. J. Bot. 87 302-313.

Panconesi, A., and Raddi, P. 1991a. Agrimed Nr. 1 e Bolgheri. Due nuove selezioni resistenti al cancro del cipresso. Cellulosa Carta 42:47-52.

Panconesi, A., and Raddi, P. 1991b. Cypress canker disease: biological and epidemiological aspects. Pages 49-60 in: Il Cipresso: Proposte di Valorizzazione Ambientale e Produttiva nei Paesi Mediterranei della Comunità Economica Europea. CNR, Regione Toscana. A. Panconesi, ed. CEE, Firenze, Italy.

Ponchet, J., and Andreoli, C. 1990. Compartmentalization and reaction in the host. Pages 96-111 in: Agriculture - AGRIMED Research Programme: Progress in EEC Research on Cypress Diseases. Report EUR 12493 EN, Commission of the European Communities. J. Ponchet, ed. Brussels, Luxembourg.

Raddi, P., and Panconesi, A. 1981. Cypress canker disease in Italy: biology, control possibilities and genetic improvement for resistance. Eur. J. Forest Pathol. 11:340-347.

Ribeiro, V. C., and Leitão, C. A. E. 2020. Utilisation of Toluidine blue O pH 4.0 and histochemical inferences in plant sections obtained by free-hand. Protoplasma 257:993-1008.

Spanos, K. A., Pirrie, A., Woodward, S., and Xenopoulos, S. 1999. Responses in the bark of Cupressus sempervirens clones artificially inoculated with Seiridium cardinale under field conditions. Eur. J. Forest Pathol. 29: $135-142$.

Suto, Y. 1998. Traumatic resin-canal formation caused by inoculation with Cistella japonica in secondary phloem of Chamaecyparis obtusa. J. For. Res. 3:99-102.

Tomlin, E. S., Alfaro, R. I., Borden, J. H., and He, F. 1998. Histological response of resistant and susceptible white spruce to simulated white pine weevil damage. Tree Physiol. 18:21-28.

Trump, B. F., Smuckler, E. A., and Benditt, E. P. 1961. A method for staining epoxy sections for light microscopy. J. Ultrastruct. Res. 5:343-348.

Xenopoulos, S., Andreoli, C., Panconesi, A., Pinto Ganhao, J., and Tuset, J. 1990. Importance of cypress. Pages 1-13 in: Agrimed Res. Programme. Prog. EEC Res. Cypress Dis. Rep. EUR 12493 EN. J. Ponchet, ed. Luxembourg.

Yamanaka, K. 1984. Normal and traumatic resin-canals in the secondary phloem of conifers. J. Jpn. Wood Res. Soc. 30:347-353.

Yamanaka, K. 1989. Formation of traumatic phloem resin canals in Chamaecyparis obtusa. IAWA J. 10:384-394. 